\title{
高分子溶液中に末ける液滴の変形*
}

\author{
荒 川 美 恵子**
}

\section{Observations on Deformation of Drops in Polymer Solutions}

by

\author{
Mieko ARAKawa \\ (Institute of Physics, Keio University, Yokohama)
}

\begin{abstract}
Observations have been performed of liquid drops suspended in several chain polymer solutions with respect to their small deformation individually.

Two flow systems have been set up in which the drops or bubbles are subject to streaming with pure shear and to uniform streaming at low constant speed. In the first case, the theoretical formula derived by Taylor is compared with the experimental results, which show that though the deformation is always linear with the applied shear, both larger and smaller deformations than those expected theoretically take place. It has become evident that there are other important factors than the shear rate, interfacial tension and viscosity, i.e. concentration of the solution, C, and the degree of polymerization of the solution, $n$ for the same kind of liquid system. The diagrams of the dimensionless deformation vs. shear rate indicate that they contribute to the drop deformation in the form $C n$.

For the second case of uniform streaming, gas bubbles deform into various shapes. Qualitative interpretation of the shape is also possible in terms of $C n$.
\end{abstract}

(Received Feb. 1, 1971)

\section{1 緒言}

粘性液体の中を 1 個の気流 5 や液滴もしくは変形し 万る固体粒子が定常運動するときにこれらの粒子は球 形からずれて変形を起こすのが普通である。レイノル ズ数がかなり小さければこの变形関する扣もな因子 として流れの速度, ずり速度, 圧力こう配などのほか に粘性率と界面張力が重要である. Taylor は Stokes 方程式を解いて純粋ずりの流れの中の液滴が球からわ ずかに変形しているときの界面の形をこれらの量であ らわしている。 また Matunobu は任意の速度分布を るつ流れの中に懸濁している液滴の変形を求めている. 理論的に予想されることは液滴の変形を決定するのは 液滴よりもととの媒質液体の性質である。

ここでは媒質液体として低いずり速度でニュートン 性を示す鎖状高分子の溶液を用い, レイノルズ数の小 さい流れの中でそれが液滴の变形に抢よぼす影響を実 験的にくわしく調べるのが目的である。

これまでに純粋ずりの流れの中の液滴については, Taylor 物よび Rumscheidt と Mason そょるもの, また一様流については Fararoui と Kintner 拈よび Arakawa と Matunobu による実験がある.

* 原稿受理 昭和 46 年 2 月 1 日

** 慶応義塾大学物理学教室 横兵市港北区日吉町

\section{2 実験の方法}

純粋ずりの流れを得るために Taylor の用いた装置 をいくぶん変更して用いた（Fig.1），鉛直に拈いた円 柱を直流モーターにつないで矢印で示した方向に回転
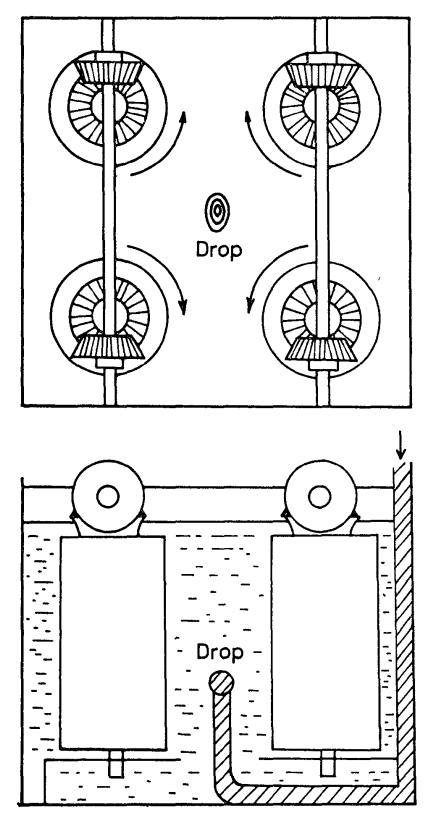

Fig. 1. Sketch of the main apparatus. 
させる.この 4 個の回転している円柱を媒質液体の中 に和くと双曲線状の流線が生じその中心付近は近似的 に純粋ずりの流れとみられる。

円柱は直径 $2 \mathrm{~cm}$ 高さ $5 \mathrm{~cm}$ のベークライト製のも ので中心を一辺が $5.5 \mathrm{~cm}$ の正方形の頂点に和き, こ れを $14 \times 14 \times 8 \mathrm{~cm}$ の媒質液体をみたしたガラス容器 の中にいれた，液滴をいつも流れの場の中心に正確に 固定するのが難しいので容器の底面を通して直径 0.3 $\mathrm{cm}$ のガラスパイプを容器内に導きその端がつねに流 れの中心になるようにして液滴をこの先に固定する。

流れの場はつぎのようにあらわされる。

$$
u=A x, v=-A y
$$

ずり速度の大きさをあらわす $A$ は円柱の回転数によっ て変化する。モーターの電圧を調整して回転数を变化 させ，抢よそ $0.2 〜 10 \mathrm{sec}^{-1}$ の範团について実験をし た。用いた媒質液体はポリエチンングリコール(PEG： 平均分子量 $400,1500,4000,6000)$ とシリコンオ イル (DMPS: 平均分子量 $6.60 \times 10^{3}, 7.99 \times 10^{4}$, $\left.9.44 \times 10^{4}\right)$ である. PEG は蒸留水を DMPS はパーク ロルエチレンを溶剤として10～12段階の濃度の異なる 媒質液体を作った，回転粘度計の回転数を連続的に変 化して測定した結果，実験を行なったずり速度の範囲 ではいずれの場合もニュートン性を示している. 分散 液体（液滴）は流動パラフィン,パークロルェチレン, グリセリン，ェチルアルコール，水などのうら 2 種の 液体を混合して媒質液体と同じ比重になるようにして 重力の影響を除いた。液滴はずり速度の増すのにつれ て球から扁平に変形する. 円柱の回転状態が定常にな ったときに液滴をカメラで接写して大きさと形を読み とった。

\section{3 実験結果および考察}

（1）純粋ずりのある流れの中の液㼺

液滴はずり速度が増すのにつれて球形から扁平にな っていき，やがてもぎれて分散するという過程をたど る. Taylor の理論によれば変形をあらわすパラメー タとして液滴の縦横の径 $L, B$ をるとにた比 $G(=$ $(L-B) /(L+B))$ は変形が小さいときつぎの式であら わされる。

$$
G=\frac{2 A \mu_{c} a}{T} \frac{19 \lambda+16}{16(\lambda+1)}
$$

ここでAはずり速度， $a$ は液滴と同体積の球の半径， $T$ は界面張力, $\mu_{c}$ は媒質液体 $\mu_{d}$ は液滴の粘性率, $\lambda$ はその比 $\left(\lambda=\mu_{d} / \mu_{c}\right)$ をあらわす. Taylor はまた が0.0003〜20の液体の組合わせについて実験を行ない， ずり速度の小さいうちは上式であらわした理論值とよ く一致することを報告している。液滴の変形には液滴 内部の循環流が影響をもつと考えられる。液滴の境界 面での循罍流の速度は $2 A a /(\lambda+1)$ であらわされる.
したがって液滴境界面での速度を含む無次元量として

$$
F=\frac{2 A \mu_{c} a}{T(\lambda+1)}
$$

を選ぶことにしよ5。(1)式より

$$
F=\frac{2 A \mu_{c} a}{T(\lambda+1)}=G \frac{16}{19 \lambda+16}
$$

いま, 無次元の変形量

$$
D=G \frac{16}{19 \lambda+16}=\frac{L-B}{L+B} \frac{16}{19 \lambda+16}
$$

をとり，FとDの関係を調べょう。 Taylor の(1)式は $D=F$ となる.

それぞれの液体系に対する $D-F$ の関係をFig. 2 と Fig. 3 に示す. Fが増すのにつれてDは直線的に増加 しているがとの増加率は液体の濃度によって異なり,

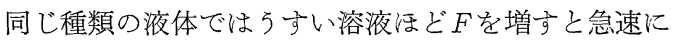
扁平になっていくことを示している。図中の実線は Taylor の理論特よび実験結果をあらわし, 破線は Mason の実験のうち $\lambda=1$ の結果を示している. Taylor 拈よび Mason の実駼結果に比べてわれわれ の実験結果はかなり広いばらつきを示している。

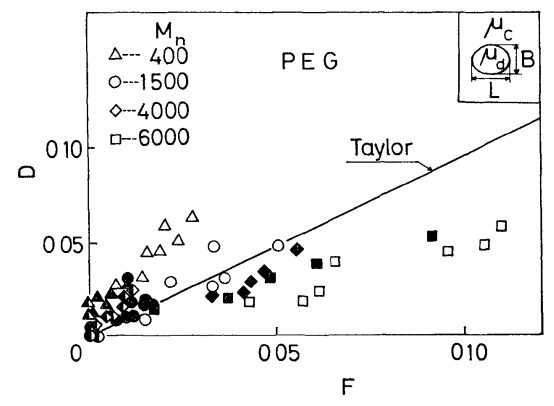

F1g. 2. Deformation vs. shear rate in hyperbolic flow for PEG.

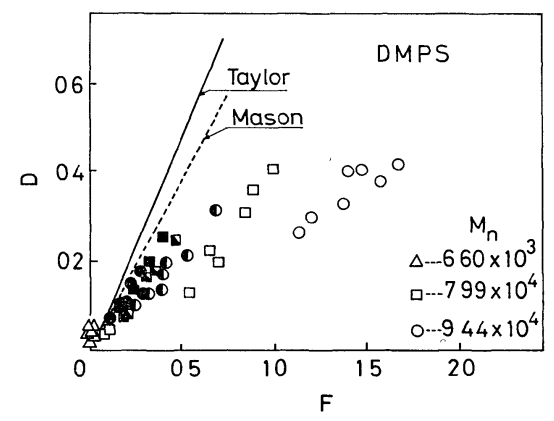

Fig. 3. Deformation vs. shear rate in hyperbolic flow for DMPS.

媒質液体の粘性率が変形に扣よぼす影響をしらべて みる (Fig. 4 と Fig. 5). それぞれの $\mu_{c}$ に対して $D$ 一 $F$ 直線のこう配をプロットした。 $\mu_{c}$ が高くなるに つれてこう配 $D / F$ が直線的に減少しているがその様 子は液体の種類によって違っている.どちらの場合も 


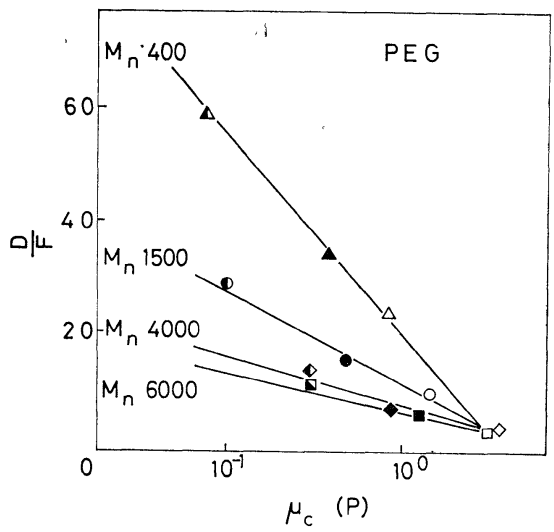

F1g. 4. Effect of viscosity of the continuous phase on the drop deformation for PEG.

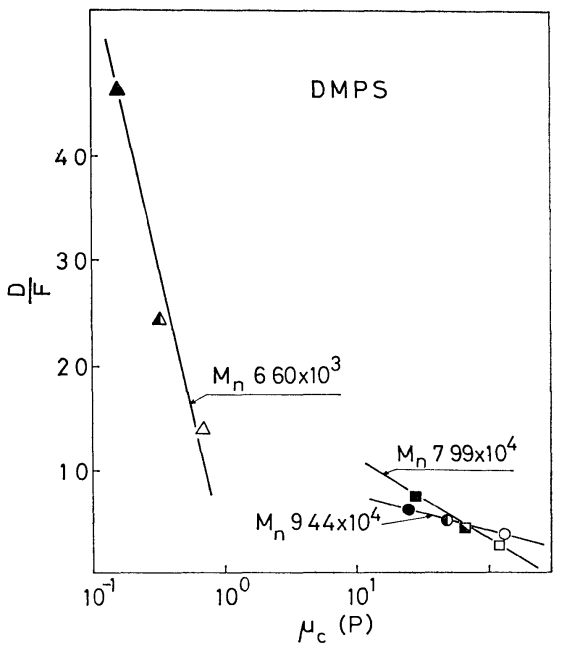

Fig. 5. Effect of viscosity of the continuous phase on the drop deformation for DMPS.

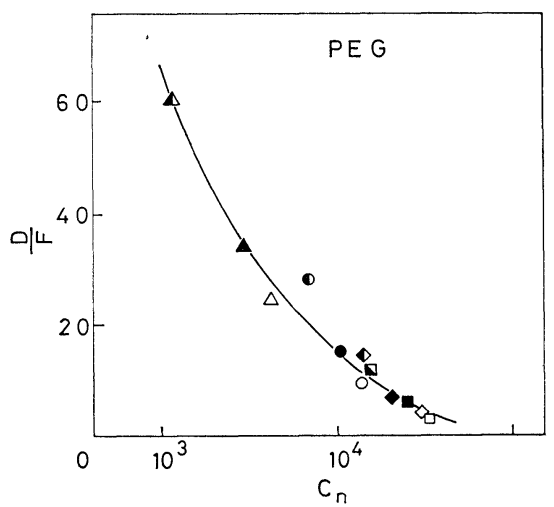

F1g. 6. Effect of the degree of polymerization $n$ and the concentration $C$ on the drop deformation for PEG.

分子量の小さいものほど同じ $\mu_{c}$ でもこう配 $D / F$ は 大きい. 同じ $\mu_{c}$ に対して分子量の小さいものの方が 同じずり速度についておきる变形の割合は大きいとい

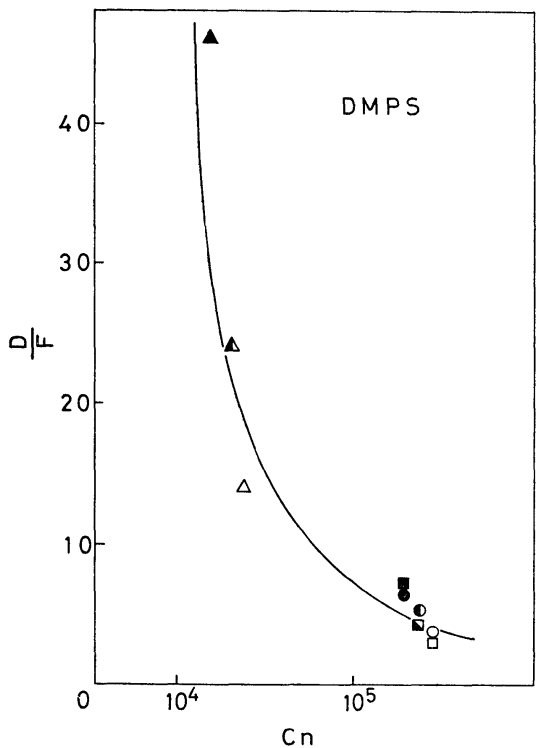

Fig. 7. Effect of the degree of polymerization $n$ and the concentration $C$ on the drop deformation for DMPS.

う傾向を示していることがわかる。

この $D / F$ の值を媒質液体の濃度 $C(=g / l)$ と重合 度 $n$ の積 $C n$ を横軸として整理してみよう（Fig. 6 之 Fig.7)。それどれについてみると溶液の濃度による違 いは消光て添 1 本の線にのるものとみてよい。Cn の小さいものほど $D / F$ の值は大きく，Cn の増加に つれて急速に減少していくことがわかる。したがって $D / F$ の $C n$ に対する低存性は同じ種類の液体系につ いてはほぼ1本の線で代表されることがみられる。

(2) 一様流の中の気注了

重力場で運動する液滴や気ほ らは体積が増加するに つ机移動速度を増して変形するがそれは拉よ先つぎの 2 つのタイプに分類される.

(a) 球形から扁平な形へと変形していくもの

(b) 球形加ら運動方向に縦に長く变形しその後端 がとがってくるもの（これはさらに体積を増 すと扁平になり平凸レンズ状へと移行する)

分子量が普通大の媒質液体では(a)のタイプが生ずるが 分子量の大きい場合は(b)の異常変形が拈さるものとみ られる. Fararoui と Kintner は(b)のタイプの変形は 媒質液体の非ニュートン性が原因であると指摘してい る。しかしこれまでの観察ではたと光ば Plexol（ポ リイソブチレンの 1 種）の中を上昇する気潘うの場合 のよ5に上昇速度が小さく汪とんどニュートン性とみ られる場合でもとがった変形がみられることがある。 タイプ(b)の変形は分子量の大きい溶質を含む溶液に特 有の現象であることと考光合わせて，この場合にも上 に得た純粋ずりの流れに対する結論がなりたつかどう 
かを調べてみよう。

ポリビニルアルコール (PVA) の水溶液中を自由上 昇する気汪うの観測結果をCnの值を用いて気汪うの 体積が増すのにつれてどのような変形の過程をたとる かをしらべてみる.PVA は重合度が500 と 1500 の 2 種類でそれぞれ 3 段階の濃度のものである。これら溶 液の密度と界面張力の值はほとんど同じであり, 溶液 中を一定速度で上昇する気汪うを写真撮影して形を読 みとった。結果はFig. 8 のようになる.

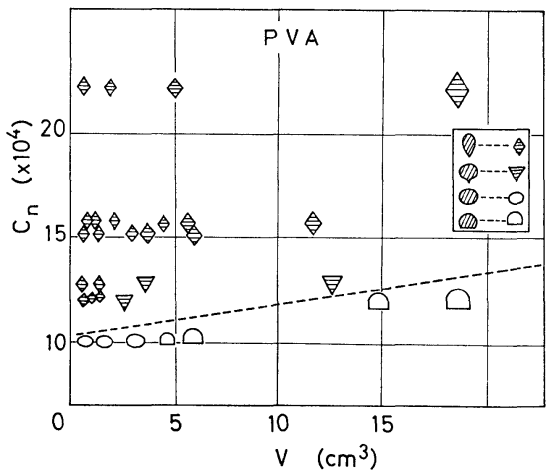

Fig. 8. Classification of the deformation based upon $\mathrm{Cn}$ for gas bubbles moving through PVA solution at constant speeds.

繸軸に溶液についてのCnを横軸に気㴗うの体積を とり, 体積の増えるのに従って変形していく様子を 4 種類に分類してあらわした．変形の状態は同じ体積の 気汪らについていえば，Cn の大きいものでは後端に とがりがあって縦に長い。C $C n$ が小さくなるととがり があって長さはだんだん短くなり，そして扁平になる。
もっとCnが小さいととがりがなくなって球状もしく は扁平球状となり，ついには平凸レンズ状となる。こ の傾向は重合度の違う液体も含めてなりたち，この結 果から後端にとがりのあらわれる領域の境界線（図の 破線）を推定することができる。このよ5に自由上昇 する気ほうの変形についても変形の性格はパラメータ $C n$ に左右されることがわかる.

以上の結果から推察すると用いた鎖状高分子の溶液 中の液滴や気ほうのふるまいについては媒質液体の粘 性率, 密度, 界面張力などのほかに, 溶質の重合度之 溶液の濃度の寄与が無視できないこと，抗よび両者の 積の形で寄与することがわかる。

終わりに本研究にあたってご指導をいただいた慶応 義塾大学松信八十男教授に厚く感謝の意を表明する. （昭和45年10月 8 日 第18回レオロジ一討論会にて講演）

\section{参 考 文 献}

1) Taylor, G I, Proc. Roy. Soc, A 146, 501 (1934).

2) Matunobu, Y., J. Phys. Soc. Japan, 29, 508 (1970).

3) Rumscheidt, F. D., and S. G. Mason, J. Collord Sc1, 16, 238 (1961).

4) Rumscheidt, F. D., and S. G. Mason, J. Colloid Sci., 16, 210 (1961).

5) Fararoui, A, and R.C., Kintner, Trans Soc. Rheol., 5, 369 (1961).

6) Arakawa, M., and Y. Matunobu, J. Phys. Soc. Japan, 25, 1495 (1968).

7）松信八十男, 荒川美恵子, 慶応義塾大学法学研究教養論 叢, 23, 121 (1968).

\section{(629頁より)}

163. Critical concentrations of polymers in solutions according to measurements of the viscosity and specific surface area of aerogels resulting after sublimation of the solvent, G. V. Vinogradov, L. V. Titkova, 655 .

\section{Band 240}

164. Energieelastizität von Polystyrol bei der Warmverstreckung II., J. Stolting, F. H. Muller, 792.

165. Mechanical denaturation of high polymers in solution XX, K. Yamaura, S. Matsuzawa, Y. Go, 820 .

\section{Band 241}

166. Zur Deutung des Deformationsverhaltens von fadenformigen partiellkristallinen verstreckten Hochpolymeren, J. Juilfs, 897.

167. Einfluss der Quellung auf die mechanische Relaxation von Polyäthylenterephthalat, H. G. Zachmann, W. Schermann, 916.

168. Untersuchung der mechanischen Relaxation von Polyäthylenterephthalat in Abhängigkeit von den Kristallisationsbedingungen, W. Schermann, H. G. Zachmann, 921.

169. Molekülbewegung in Polymeren III teil: Mikrostruktur und mechanische Eigenschaften, W. Pehhold, S. Blasenbreg, 955.

170. Dielektrischer Verlust von Polymeren bei $75 \mathrm{GHz}$, E. Amerhein, H. W. Schulze, 1034. (637頁へ) 